\title{
Research on low temperature drying characteristics of different types of manure and biogas residue
}

\author{
Xiu Fangtao ${ }^{1}$, Zhu Hongguang ${ }^{1, *}$, Xu Yupeng ${ }^{1}$ \\ ${ }^{1}$ Bio-Energy Research Center, Institute of New Rural Development, Tongji University, Shanghai, 201804, China
}

\begin{abstract}
For the biogas project which does not have the ability to return to the field nearby, the outlet of biogas residue is one of the important bottlenecks restricting the development of biogas engineering. Deep dehydration and drying is a reliable basis for commercial utilization of biogas residue, especially combined with waste heat utilization of cogeneration of biogas. Therefore, three kinds of biogas residue raw materials were dried at low temperature by hot drying method in this paper. The drying temperature, the thickness of biogas residue and the backmixing amount of dry biogas residue were selected as three influencing factors. The drying time, drying rate and residual water ratio were taken as dependent variables. The drying characteristic curve of biogas residue was obtained, and the influence of each factor on the drying process of biogas residue was analyzed and compared. The results showed that the drying time of three kinds of biogas residue decreased with the increase of drying temperature. At the same temperature, the drying time decreases with the decrease of thickness. The dry biogas residue backmixing can't optimize the drying characteristics and even increase the drying energy consumption.
\end{abstract}

\section{Introduction}

The total amount of livestock and poultry manure in China is as high as $20.08 \times 10^{8} \mathrm{t}{ }^{[1]}$. Using anaerobic fermentation technology to use these faeces as raw materials for biogas engineering is of great significance to realize the recycling of manure. At the same time, the production of biogas residue is also huge. Biogas residue contains about $90 \%$ moisture, which is very bulky and inconvenient to store and transport.

Some studies have shown that ${ }^{[2-3]}$, the transportation cost of biogas residue and whether it is convenient to use are important factors affecting farmers' willingness to use biogas residue. Therefore, it is necessary to dry the biogas residue for further utilization. Considering that the waste heat generated by cogeneration biogas project is relatively rich, it can be used for drying biogas residue ${ }^{[4]}$, which can't only improve the energy utilization efficiency, but also realize the drying and dehydration treatment of biogas residue, which greatly improves the economic benefits of biogas engineering. The waste heat temperature of cylinder liner water of biogas generator is only about $80{ }^{\circ} \mathrm{C}$, so low temperature drying process should be adopted. Low temperature drying is conducive to the retention of nutrients in biogas residue. It can use low-grade energy such as solar energy, industrial waste heat, waste heat, etc. combined with heat pump technology with high thermal efficiency, it can achieve better energy-saving effect ${ }^{[5]}$, greatly improve energy utilization efficiency, reduce gas emissions and avoid unnecessary secondary pollution.
In order to adopt reasonable engineering technology means and process parameters, improve the drying efficiency of biogas residue and reduce the drying cost, it is necessary to study the low-temperature drying characteristics of biogas residue.

\section{Experimental materials, devices and methods}

\subsection{Experimental materials}

Biogas residue from anaerobic fermentation of pig manure, cow dung and chicken manure was selected as the research object. Among them, pig manure and biogas residue were taken from the biogas project site of Minsheng village, Chongming District, Shanghai; cow dung and biogas residue were taken from the biogas project of Xidi dairy farm in Pudong New Area of Shanghai; and the biogas residue of chicken manure was taken from a biogas project site in Longwang Township, Funan County, Anhui Province. All the above materials were separated by solid-liquid separation. When the experimental materials are not in use, they are put into a low-temperature refrigerator and sealed at $4{ }^{\circ} \mathrm{C}$. The raw material characteristics of the following types of biogas residue were obtained by testing.

Table 1. Raw material characteristics of three kinds of biogas residue

\footnotetext{
"Corresponding author's e-mail: zhuhg@tongji.edu.cn
} 


\begin{tabular}{|c|c|c|c|c|}
\hline $\begin{array}{c}\text { Type of } \\
\text { biogas } \\
\text { residue }\end{array}$ & $\begin{array}{c}\text { Moisture } \\
\text { content }\end{array}$ & TS & VS & Ash content \\
\hline $\begin{array}{c}\text { Pig } \\
\text { manure }\end{array}$ & $83.7 \%$ & $16.3 \%$ & $80.6 \%$ & $19.4 \%$ \\
\hline Cow dung & $81.4 \%$ & $18.6 \%$ & $83.7 \%$ & $16.3 \%$ \\
\hline $\begin{array}{c}\text { Chicken } \\
\text { manure }\end{array}$ & $71.4 \%$ & $28.6 \%$ & $70.5 \%$ & $29.5 \%$ \\
\hline
\end{tabular}

\subsection{Experimental devices}

In the drying oven, the biogas residue was dried in the laboratory drying oven, and weighed with Shanghai Hengping FA2004 analytical balance.

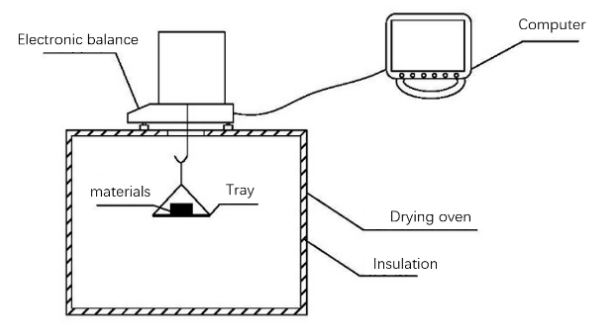

Fig. 1. Diagram of real time weighing device for biogas residue drying.

In order to realize automatic recording of experimental data, reduce the workload of laboratory personnel, and improve the accuracy of weighing, a biogas residue drying experimental device which can weigh in real time is built, as shown in Fig.1. The device is mainly composed of electric heating blast drying oven, electronic balance and computer. The electronic balance has the function of weighing at the bottom, and the top of the electric blast drying oven is provided with a vent. Through the air hole of the drying oven, a wire is used to connect the bottom scale hook of the electronic balance with the tray in the drying box. In this way, the electronic balance can display the material quality in the drying process in real time when the materials are placed in the tray for drying. The electronic balance is connected with the computer through RS232 serial port, the small program is written on the computer by VB language, and the communication is established. The real-time data acquisition of drying process can be realized.

\subsection{Experimental methods}

The static drying method was used in the experiment. The specific surface area of biogas residue was 333.33, $166.67,111.11,83.33$ and $66.67 \mathrm{~m} 2 / \mathrm{m} 3$, respectively, with the thickness of 3, 6, 9, 12 and $15 \mathrm{~mm}$. The cylinder liner water temperature of biogas generator in cogeneration is about $80{ }^{\circ} \mathrm{C}$. In order to study the use of this heat to dry biogas residue at low temperature, five temperatures of $40{ }^{\circ} \mathrm{C}, 50{ }^{\circ} \mathrm{C}, 60{ }^{\circ} \mathrm{C}, 70{ }^{\circ} \mathrm{C}$ and $80{ }^{\circ} \mathrm{C}$ were set. Through the thermogravimetric analysis of three kinds of biogas residue, it is found that the temperature of volatile matter is about $200{ }^{\circ} \mathrm{C}$, and the evaporation of water occurs mainly when the temperature is below $80{ }^{\circ} \mathrm{C}$, and there is no loss of volatile matter or little water relative to evaporation. Therefore, it can be ignored when studying the drying characteristics of biogas residue. In order to study its effect on the drying characteristics of biogas residue, five backmixing amounts of $0 \%, 5 \%, 10 \%, 15 \%$ and $20 \%$ were set up.

The temperature is controlled by setting the temperature of drying oven. For the influence of biogas residue thickness, the hollow cylinder with different thickness (4 $\mathrm{cm}$ inner diameter) was made by hand with PVC pipe as the mold of biogas residue. The back mixing of dry biogas residue is achieved by controlling the addition amount of absolutely dry biogas residue. The completely dry biogas residue is crushed and screened, and mixed with wet biogas residue according to different mass ratio. In order to ensure the full and uniform distribution of water, the sample is prepared one day in advance and stored in an ice box at $4{ }^{\circ} \mathrm{C}$. The specific experimental conditions are shown in Table 2. The drying experiments were carried out according to the working conditions in the table. After drying to equilibrium, the oven was heated to $105^{\circ} \mathrm{C}$ for two hours to determine the equilibrium moisture content of biogas residue.

Table 2. Raw material characteristics of three kinds of biogas residue

\begin{tabular}{|c|c|c|c|}
\hline $\begin{array}{c}\text { Serial } \\
\text { number }\end{array}$ & $\begin{array}{c}\text { Temperature } \\
\left({ }^{\circ} \mathrm{C}\right)\end{array}$ & $\begin{array}{c}\text { Thickness } \\
(\mathrm{mm}) / \\
\text { Specific } \\
\text { surface area } \\
\left(\mathrm{m} 2 / \mathrm{m}^{3}\right)\end{array}$ & $\begin{array}{c}\text { Backmixing } \\
\text { of dry biogas } \\
\text { residue }\end{array}$ \\
\hline 1 & 40 & $9 / 111.11$ & $0 \%$ \\
\hline 2 & 50 & $9 / 111.11$ & $0 \%$ \\
\hline 3 & 60 & $9 / 111.11$ & $0 \%$ \\
\hline 4 & 70 & $9 / 111.11$ & $0 \%$ \\
\hline 5 & 80 & $9 / 111.11$ & $0 \%$ \\
\hline 6 & 60 & $3 / 333.33$ & $0 \%$ \\
\hline 7 & 60 & $6 / 166.67$ & $0 \%$ \\
\hline 8 & 60 & $12 / 83.33$ & $0 \%$ \\
\hline 9 & 60 & $15 / 66.67$ & $0 \%$ \\
\hline 10 & 60 & $9 / 111.11$ & $5 \%$ \\
\hline 11 & 60 & $9 / 111.11$ & $10 \%$ \\
\hline 12 & 60 & $9 / 111.11$ & $15 \%$ \\
\hline 13 & 60 & $9 / 111.11$ & $20 \%$ \\
\hline
\end{tabular}

\section{Experimental results and analysis} 3.1 Effect of drying temperature on drying
characteristics of three kinds of biogas residue 
At different drying temperatures, the changes of mass with time of three kinds of biogas residue with thickness of $9 \mathrm{~mm}$ are shown in Fig. 2.(a), 3.(a), 4.(a). According to the change of biogas residue mass, the change of water ratio with time is shown in Fig. 2.(b), 3.(b), 4.(b). It can be seen from the figure that with the increase of drying temperature, the time for biogas residue drying to reach equilibrium is shortened. The results showed that the drying time of pig manure biogas residue was $1678 \mathrm{~min}, 1054 \mathrm{~min}$, 682 min, 529min, $413 \mathrm{~min}$, the drying time of cow dung biogas residue was $988 \mathrm{~min}$, $670 \mathrm{~min}, 487 \mathrm{~min}, 383 \mathrm{~min}, 310 \mathrm{~min}$, and the drying time of chicken manure biogas residue was $1262 \mathrm{~min}$, $878 \mathrm{~min}, 697 \mathrm{~min}, 559 \mathrm{~min}$ and $528 \mathrm{~min}$, respectively. Therefore, properly increasing the temperature can shorten the drying time and improve the drying efficiency. It can also be seen from Fig. 2.(b), 3.(b), 4.(b) that the drying time is not uniformly shortened with the increase of drying temperature. Compared with the time to reach equilibrium at $60{ }^{\circ} \mathrm{C}$, pig manure biogas residue is shortened by $59.4 \%$, cow dung biogas residue by $50.7 \%$, chicken manure biogas residue by $44.8 \%$. When the temperature rises from $60{ }^{\circ} \mathrm{C}$ to $80{ }^{\circ} \mathrm{C}$, the drying time of pig manure biogas residue is shortened by $39.4 \%$, the drying time of cow dung biogas residue is shortened by $36.3 \%$, and the drying time of chicken manure biogas residue is shortened by $24.2 \%$. With the increase of drying temperature, the distance between two adjacent curves gradually becomes smaller, which means that the influence of temperature on drying time is not obvious, and the increase of drying temperature will lead to more energy loss. Therefore, in the selection of drying temperature, it is necessary to balance the two aspects of drying efficiency and energy loss caused by temperature rise.

The curves of drying rate changing with moisture content of dry basis for three kinds of biogas residue with thickness of $9 \mathrm{~mm}$ under different drying temperature are shown in Fig. 2.(c), 3.(c), 4.(c). It can be seen from the figure that the drying rate curves of the three kinds of biogas residues at different drying temperatures are composed of the rising drying section and the falling drying section, and there is no obvious constant drying process. The higher the drying temperature is, the higher the drying rate is. With the increase of drying temperature, the moisture content of dry basis corresponding to the maximum drying rate moves to the right.

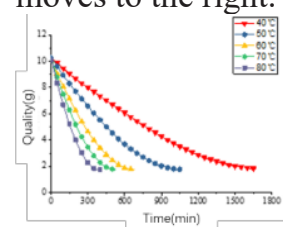

(a)

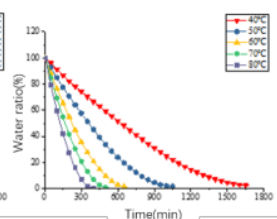

(b)

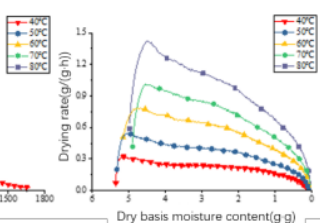

(c)
Fig. 2. Variation curves of mass, water ratio and dry base moisture content of $9 \mathrm{~mm}$ pig manure biogas residue at different drying temperatures

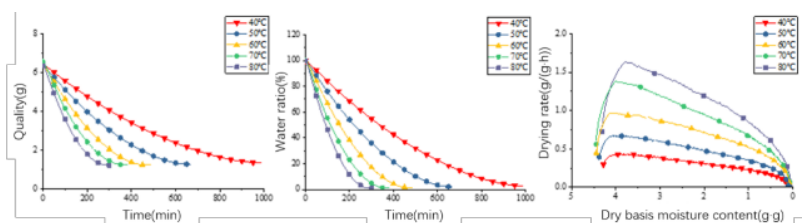

(a)

(b)

(c)

Fig. 3. Variation curves of quality, water ratio and drying rate of $9 \mathrm{~mm}$ cow dung biogas residue at different drying temperatures

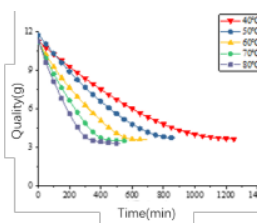

(a)

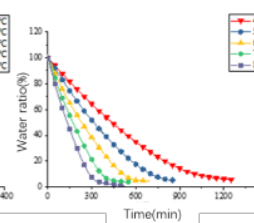

(b)

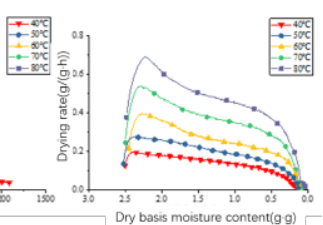

(c)
Fig. 4. Variation curves of quality, water ratio and drying rate of $9 \mathrm{~mm}$ chicken manure biogas residue at different drying temperatures

\subsection{Effect of thickness on drying characteristics of three kinds of biogas residue}

Under the condition of $60{ }^{\circ} \mathrm{C}$, the variation curves of mass with time of three kinds of biogas residue with different thickness (specific surface area) during drying are shown in Fig. 5.(a), 6.(a), 7.(a). It can be seen from the figure that the mass change curves of different thicknesses decrease approximately linearly at the initial stage and are parallel to each other, indicating that the average water evaporation per unit time of biogas residue is approximately equal, and the thickness has little effect on the water loss rate in the initial stage. However, with the extension of drying time, the curve gradually flattened, indicating that the water loss rate decreased.

According to the change of biogas residue mass, the change of water ratio with time can be calculated, as shown in Fig. 5.(b), 6.(b), 7.(b). It can be seen from the figure that the drying time increases with the increase of biogas residue thickness. When the thickness of biogas residue increased from $3 \mathrm{~mm}$ to $15 \mathrm{~mm}$, the drying time of pig manure biogas residue was $229 \mathrm{~min}, 446 \mathrm{~min}$, 682min, 975, min $1217 \mathrm{~min}$, the drying time of cow dung biogas residue was $155 \mathrm{~min}$, 316min, 487min, 655min, $857 \mathrm{~min}$, the drying time of chicken manure biogas residue was $231 \mathrm{~min}, 387 \mathrm{~min}, 697 \mathrm{~min}$, 926 min and 1121 min. The drying time of pig manure, cattle manure and chicken manure were $66.4 \%, 68.2 \%$ and $66.9 \%$ respectively. Therefore, reducing the thickness of biogas residue can shorten the drying time. When the thickness of biogas residue decreased from $9 \mathrm{~mm}$ to $3 \mathrm{~mm}$, the drying time of pig manure was shortened by $66.4 \%$, the cow dung was shortened by $68.2 \%$, the chicken manure was shortened by $66.9 \%$. Therefore, reducing the thickness of biogas residue can shorten the drying time. Under the condition of $60{ }^{\circ} \mathrm{C}$, the curves of drying rate with time of three kinds of biogas residue with different 
thickness are shown in Fig. 5.(c), 6.(c), 7.(c). It can be seen from the figure that the drying rate curve of biogas residue with different thickness is still composed of rising drying section and falling drying section. Under the same moisture content of dry basis, the thinner the biogas residue thickness, the faster the drying rate.

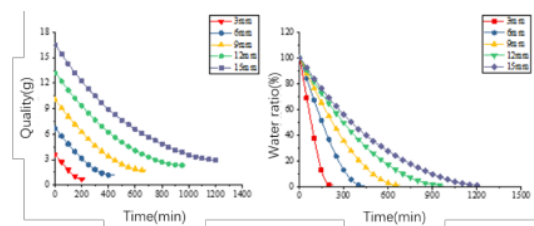

(a) (b)

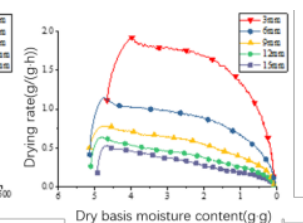

(c)

Fig. 5. Variation curves of quality, water ratio and drying rate of pig manure biogas residue with different thickness at $60{ }^{\circ} \mathrm{C}$

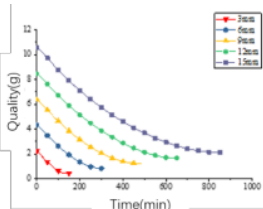

(a)

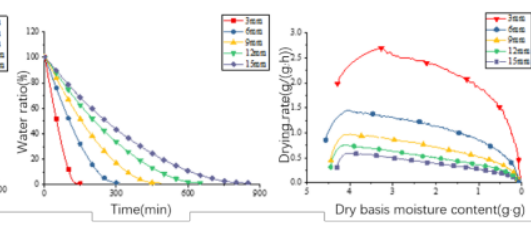

(b)

(c)
Fig. 6. Variation curves of quality, water ratio and drying rate of cow dung biogas residue with different thickness at $60^{\circ} \mathrm{C}$

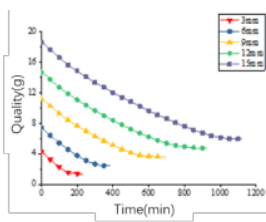

(a)

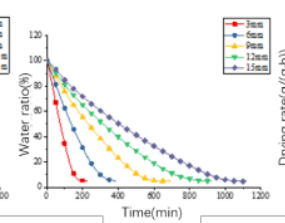

(b)

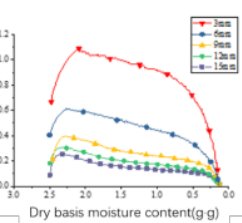

(c)
Fig. 7. Variation curves of quality, water ratio and drying rate of chicken manure biogas residue with different thickness at $60{ }^{\circ} \mathrm{C}$

\subsection{Effect of backmixing amount of dry biogas residue on drying characteristics of three kinds of biogas residue}

Under the condition of $60{ }^{\circ} \mathrm{C}$, the variation curves of three kinds of biogas residue quality with time are shown in Fig. 8.(a), 9.(a), 10.(a). With the increase of the amount of dry biogas residue back mixing, the mass and density of biogas residue sample decrease, and the quality change is more gentle, which indicates that the water loss rate of dry biogas residue after backmixing decreases.

The change of biogas residue mass ratio with time can be calculated as shown in Fig. 8.(b), 9.(b), 10.(b). Under the conditions of $0 \%, 5 \%, 10 \%, 15 \%$ and $20 \%$ of dry biogas residue, the corresponding initial moisture content of pig manure biogas residue was $83.7 \%, 79.2 \%$, $76.5 \%, 73.5 \%$ and $71.4 \%$, the initial moisture content of cow dung biogas residue was $81.4 \%, 78.0 \%, 75.3 \%$, $70.4 \%$ and $68.3 \%$, and that of chicken manure was $71.4 \%, 68.1 \%, 64.7 \%, 62.0 \%$ and $59.4 \%$. It can be seen from the figure that the dry biogas residue mixed with pig manure and cow manure has a certain impact on the drying time. With the increase of the amount of dry biogas residue, the drying time is shortened, but the degree of shortening is small. The results showed that the drying time of chicken manure biogas residue mixed with dry biogas residue almost had no effect on drying time, and the water ratio curves of different amount of back mixing almost coincided, and the drying time was basically the same.

At $60{ }^{\circ} \mathrm{C}$, the curves of drying rate with dry base moisture content are shown in Fig. 8.(c), 9.(c), 10.(c). It can be seen from the figure that the maximum drying rate of the three kinds of biogas residue decreases with the increase of the backmixing amount of dry biogas residue. The initial moisture content of biogas residue with different backmixing amount is different, but the drying rate curves of pig manure biogas residue and cow manure biogas residue with different backmixing amount basically coincide when the drying rate is reduced. The drying rate curve of chicken manure biogas residue with different backmixing amount was slightly higher than that with more backmixing amount.

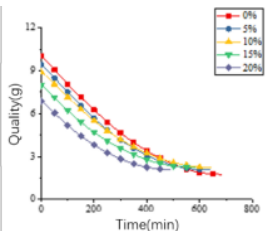

(a)

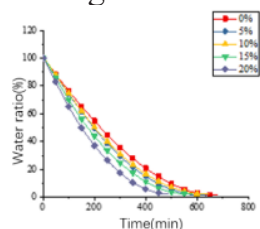

(b)

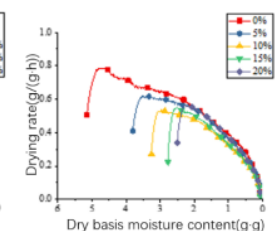

(c)
Fig. 8. Variation curves of quality, water ratio and drying rate of pig manure biogas residue with different backmixing at $60{ }^{\circ} \mathrm{C}$

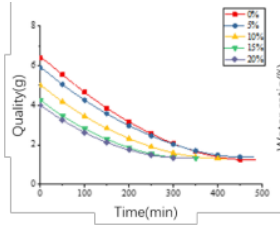

(a)

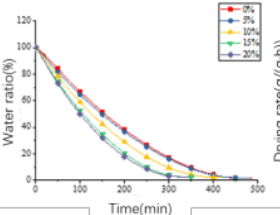

(b)

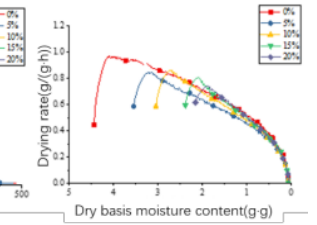

(c)
Fig. 9. Variation curves of quality, water ratio and drying rate of cow dung biogas residue with different backmixing at $60{ }^{\circ} \mathrm{C}$

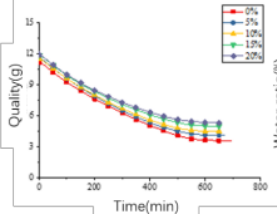

(a)

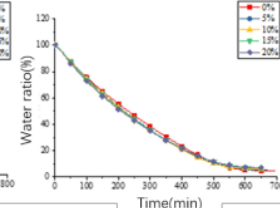

(b)

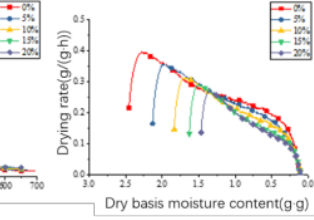

(c)
Fig. 10. Variation curves of quality, water ratio and drying rate of chicken manure biogas residue with different backmixing at $60{ }^{\circ} \mathrm{C}$

\section{Results discussion}

The drying characteristics of pig manure, cow dung and chicken manure under different conditions were studied. It was found that the drying temperature, the thickness of 
biogas residue and the backmixing amount of dry biogas residue had certain effects on the drying characteristics of biogas residue.

The drying rate curve of biogas residue under different conditions is composed of rising speed drying section and decreasing speed drying section. This is because in the initial drying stage, the biogas residue is heated, the surface water evaporation rate is accelerated, and the internal water can maintain stable diffusion to the surface, and the drying process is accelerated. When the surface water evaporation rate is greater than the transfer rate of internal water to the surface, the material drying enters the decline stage until the drying balance is reached.

(1) The higher the temperature is, the stronger the drying capacity of biogas residue is, the lower the moisture content when reaching equilibrium, the higher the drying rate and the shorter the drying time. This is because the higher the temperature is, the greater the driving force of heat transfer is, the more easily the moisture outside the material is evaporated, and the greater the moisture concentration difference between the inside and outside of the material. The difference of temperature and concentration leads to the acceleration of water diffusion rate. At the same time, the increase of temperature will also cause the internal pores of biogas residue to expand, which is conducive to the diffusion of water. However, the increase of drying temperature leads to the increase of energy consumption. Therefore, when choosing the drying temperature, we should pay attention to the relationship between the energy consumption and the drying efficiency. It can be seen from Fig. 2.(b), 3.(b), 4.(b) that with the increase of temperature, the drying time of the three kinds of biogas residue gradually becomes less obvious. Especially when the temperature rises to above $60{ }^{\circ} \mathrm{C}$, it is recommended to take the drying temperature as $60^{\circ} \mathrm{C}$.

(2) In the final analysis, the difference between biogas residue of the same type and different thickness is the difference of specific surface area. According to the ratio of dry area (inner surface area of mould $12.56 \mathrm{~mm} 2$ ) and dry weight of biogas residue samples, the specific surface area of dry basis corresponding to biogas residue with different thickness can be obtained, as shown in Table 3.1. It can be seen from the table that the larger the thickness of biogas residue of the same type, the smaller the specific surface area of dry basis mass. Therefore, with the increase of biogas residue thickness, the drying rate decreased and the drying time prolonged.

Table 1. Raw material characteristics of three kinds of biogas residue

\begin{tabular}{|c|c|c|c|c|c|}
\hline $\begin{array}{c}\text { Type of } \\
\text { biogas } \\
\text { residue }\end{array}$ & 3 & 6 & 9 & 12 & 15 \\
\hline $\begin{array}{c}\text { Pig } \\
\text { manure }\end{array}$ & 19.69 & 11.61 & 7.69 & 5.81 & 4.53 \\
\hline $\begin{array}{c}\text { Cow } \\
\text { dung }\end{array}$ & 29.69 & 16.10 & 10.72 & 8.07 & 6.28 \\
\hline $\begin{array}{c}\text { Chicken } \\
\text { manure }\end{array}$ & 10.36 & 5.94 & 3.88 & 2.99 & 2.36 \\
\hline
\end{tabular}

When the thickness of three kinds of biogas residue decreased from $6 \mathrm{~mm}$ to $3 \mathrm{~mm}$, the specific surface area of dry basis was greatly increased, and the drying rate was greatly increased. The biogas residue with thickness of $3 \mathrm{~mm}$ had the highest drying rate. However, in practical engineering, it is difficult to use the thickness of $3 \mathrm{~mm}$ for thin-layer drying. Generally, the specific surface area can be increased, the internal water diffusion of biogas residue can be improved, and the drying rate can be increased by mixing, turning and air flow. Fluidized bed drying is a typical drying method to increase the specific surface area, which can reach the specific surface area equivalent to or even larger than 3 $\mathrm{mm}$ thick biogas residue, so the drying rate is very high.

(3) The effect of dry biogas residue backmixing on drying time of biogas residue was not obvious, and the drying rate decreased. When the biogas residue was dried into the reduced speed drying section, the drying rate curves of pig manure biogas residue and cow manure biogas residue with different backmixing amount were approximately coincident. This indicates that when the drying conditions are determined, the drying rate of pig manure and cattle manure biogas residue is only related to the process moisture content, but not to the initial moisture content. This result is the same as that of Zhang Xiaomin ${ }^{[6]}$ using moisture analyzer to study the drying characteristics of sludge. The results showed that the drying rate of chicken manure biogas residue decreased with the increase of the amount of dry biogas residue. This may be because there is no skeleton structure in the chicken manure biogas residue, which is easy to appear the phenomenon of internal thinning and external drying. When the drying speed is reduced, the lower the backmixing amount of dry biogas residue is, and when the same water content is reached, the more external water loss of chicken manure biogas residue is, and the higher the uneven degree of internal and external moisture is, the faster the internal moisture diffuses outward. In addition, the backmixing of dry biogas residue will cause repeated drying of the back mixing part, which will reduce the effective amount of single drying and the drying efficiency.

\section{References}

1. Chen Lihong, Shu Bangrong and Li Xin, China's livestock manure biogas potential and influencing factors evaluation based on regional differences in excretion coefficient. China Biogas, 2019. 37(02): Page 7-11.

2. Gong, H., et al., Concentrating process of liquid digestate by disk tube-reverse osmosis system. Desalination, 2013. 326: P 30-36.

3. Zhang Guozhi et al., Investigation and analysis of the status quo of biogas residue utilization of large and medium-sized biogas projects. China Biogas, 2010. 28(1): Page 21-24.

4. Moller J, Boldrin A, Christensen T H. Anaerobic digestion and digestate use: accounting of greenhouse gases and global warming contribution. 
Waste Management \& Research the Journal of the International Solid Wastes \& Public Cleansing Association Iswa, 2009, 27(8):813-824.

5. Yu Zhenwei et al., Study on drying characteristics and drying model of organic sludge, Journal of agricultural machinery, 2017(10):286-291.

6. Zhang Xiaomin, Study on extrusion molding and drying characteristics of dewatered sludge, 2012. 